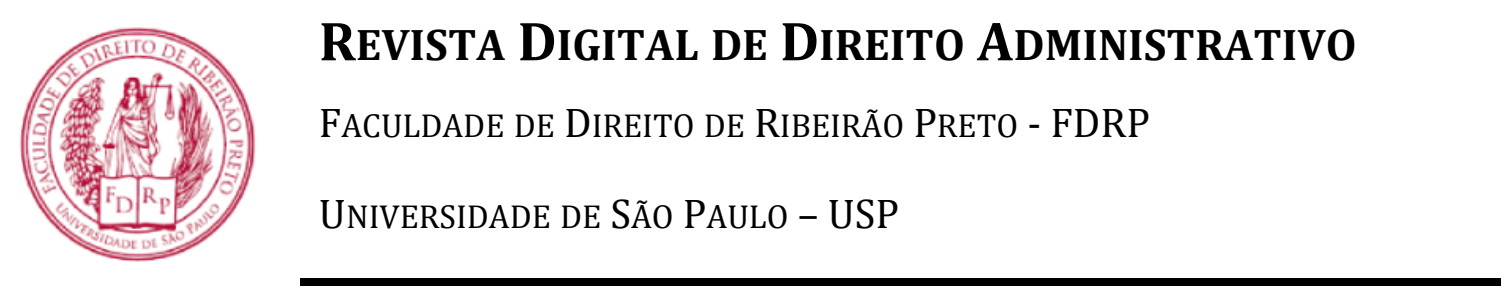

Seção: Artigos Científicos

\title{
Extinção da relação jurídica criada por ato administrativo válido e concreto sob a ótica do direito dos administrados
}

\author{
Extinction of the legal relationship created by a valid and concrete administrative act under the ad- \\ ministered's right
}

\section{André Paulani Paschoa}

\begin{abstract}
Resumo: Estudo teórico que aborda as relações jurídicas formadas entre Administração Pública e administrado decorrentes de atos administrativos concretos. Cada um dos meios de extinção da relação jurídica é discutido para compreender qual é o impacto aos direitos dos administrados na dissolução da relação jurídica. As reflexões necessariamente passam a tratar sobre a necessidade de ser desconstituída a relação jurídica pelo Estado. Caminha-se no sentido de aproximar conceitos que doutrinariamente são tratados como apartados, especialmente os de retirada de ato administrativo por meio de derrubada/contraposição e de retirada de ato administrativo por meio de decaimento/caducidade. Por força da presunção de legitimidade dos atos administrativos, propõe-se uma solução teórica que aproxime os dois conceitos doutrinários para compreender o fenômeno jurídico estudado. Por fim, com base nessa proposição, afirma-se que os direitos adquiridos pelos administrados não podem ser afetados por norma legal posteriormente emitida.
\end{abstract}

Palavras-chave: ato administrativo, direito adquirido, presunção de legitimidade

\begin{abstract}
Theoretical study that addresses the legal relationships formed between Public Administration and the administered resulting from concrete administrative acts. All the ways of the legal relationship extinction are explained to understand how the legal relationship dissolution impact on the administered's rights. The thoughts necessarily start to deal with the State's obligation to deconstruct the legal relationship. Concepts that are doctrinally treated as separate are approximate, especially those of removing an administrative act through overthrow and removing an administrative act through decay. Due to the presumption of legitimacy of administrative acts, a theoretical solution is proposed for understand the studied legal phenomenon by approximating both concepts. Finally, based on this proposition it is stated that the rights acquired by the administered cannot be affected by a legal rule issued subsequently.
\end{abstract}

Keywords: administrative act, acquired right, presumption of legitimacy

Disponível no URL: www.revistas.usp.br/rdda

DOI: http://dx.doi.org/10.11606/issn.2319-0558.v7n2p292-309

Este conteúdo está protegido pela lei de direitos autorais. É permitida a reprodução, desde que indicada a fonte como "Conteúdo da Revista Digital de Direito Administrativo". A RDDA constitui periódico científico da FDRP/USP, cuja função é divulgar gratuitamente pesquisa na área de direito administrativo. Editor responsável: Professor Associado Thiago Marrara. 


\title{
EXTINÇÃO DA RELAÇÃO JURÍDICA CRIADA POR ATO ADMINISTRATIVO VÁLIDO E CONCRETO SOB A ÓTICA DO DIREITO DOS ADMINISTRADOS
}

\author{
André Paulani PASCHOA*
}

\begin{abstract}
Sumário: 1 Introdução e recorte metodológico; 2 Formas de extinção dos efeitos do ato administrativo concreto; 3 Solução teórica proposta; 4 Referências bibliográficas
\end{abstract}

\section{Introdução e recorte metodológico}

O presente estudo pretende desenvolver alguns critérios para auxiliar na interpretação doutrinária do Direito relacionada à extinção da relação jurídica criada entre administrado e Estado decorrente de ato administrativo concreto e produzido com validade. Ainda, quer compreender qual é a relação da extinção dessa relação em face do direito dos administrados ${ }^{1}$.

A produção de normas jurídicas exige uma série de pressupostos para que sua emissão seja realizada em conformidade com o Direito. Especificamente quanto aos atos administrativos, entende-se que são válidos aqueles que são produzidos em conformidade com o ordenamento ou cuja desconformidade seja desprezível ${ }^{2}$.

Produzidos com validade e superada qualquer outra pendência (termo, condição suspensiva, decisão de autoridade controladora etc.) que os condicione, os atos es-

\footnotetext{
* Mestrando em Direito Administrativo na Pontifícia Universidade Católica de São Paulo (PUC-SP), bacharel pela mesma universidade. Advogado no escritório Dal Pozzo Advogados. E-mail: paschoandre@gmail.com

${ }^{1}$ Já em 1980 o norteamento teórico do professor Celso Antônio Bandeira de Mello sempre foi o de proteção aos administrados como objetivo do Direito Administrativo. Escreveu o mestre paulista ao expor, na Introdução, o porquê de ter nomeado seu livro de Ato Administrativo e Direitos dos Administrados: "Nosso propósito neste passo foi, justamente, exibir a verdade curial de que, no Estado de Direito, a própria noção de ato administrativo, sua estrutura e pressupostos de validade, trazem consigo, de par com as prerrogativas públicas, limites incontendíveis. Deles resultam consequências exaltadoras de direitos para os administrados. (...)

Não se deverá depreender desta "Introdução" que o presente livro examina politicamente temas jurídicos. Mantivemo-nos sempre, ao longo de suas páginas e muito ao de ministro, aferrados à dogmática do Direito. Há, talvez, um vetor político, no título, como há também, isto sim, uma intenção política ao eleger a temática. Com efeito, os assuntos versados são dos mais propícios a desvelar os condicionantes jurídicos - que servem, pois, de limites - a ação administrativa do Estado. Esta intenção política é, no fundo, o compromisso que todos os estudiosos do Direito devem ter como a legitimidade, na medida em que se constitui num valiosíssimo instrumento para defesa e garantia da liberdade" [MELLO, 1991, pp. IX-X]

2 É a linha do professor Ricardo Marcondes Martins nesta lição: "O estudo dos pressupostos de regularidade indica se o ato é viciado - se contraria o Direito - ou não e, pois, se é inválido - se, além de contrariar o Direito, este exige, no momento subsequente à introdução do ato, a correção do vício - ou não." [MARTINS, 2019, p. 244]
} 
tão aptos a gerar os seus efeitos ${ }^{3}$. Restringindo ainda mais: o efeito da criação de um ato administrativo concreto válido e eficaz é a criação da relação jurídica entre o administrado e a Estado, representado pela Administração Pública.

Os atos administrativos concretos são aqueles que estabelecem uma relação jurídica entre o administrado e a Administração Pública. Cumprem, portanto, seu objetivo como norma quando estabelecem a relação jurídica e, por tal razão, extinguem-se. A conduta que preordenam é: configurada a hipótese fática, estabeleça-se a relação jurídica. Não se tratará aqui, portanto, de regulamentos ou de outra forma de atos abstratos ${ }^{4}$.

Importante, ainda, fazer mais uma constatação: apoia-se aqui na teoria dos professores Celso Antônio Bandeira de Mello ${ }^{5}$ e Márcio Cammarosano ${ }^{6}$, qual seja, a de que o ato concreto é aquele que, concretizada a eficácia, construída a relação jurídi-

3 “O ato administrativo é eficaz quando está disponível para a produção de seus efeitos próprios; ou seja, quando o desencadear de seus efeitos típicos não se encontra dependente qualquer evento posterior como uma condição suspensiva, termo inicial ou ato controlador a cargo de outra autoridade." [MELLO, 2016, p. 400].

4 "O fato de a lei ser geral e abstrata - concorrendo, então, para prestigiar os valores de impessoalidade e da igualdade, na medida em que tal estrutura normativa embaraça naturalmente as perseguições e favoritismos - não é a única razão que justificaria confiar-se ao Poder Legislativo o delicado mister de disciplinar a liberdade e a propriedade das pessoas.

Com efeito, os regulamentos também são, normalmente, gerais e abstratos. Contudo, há diferenças extremamente relevantes entre eles e as leis. Estas diferenças, a seguir referidas, ensejam que as leis ofereçam aos administrados garantias muitas vezes superiores às que poderiam derivar unicamente das características de abstração e generalidade também encontradiças nos regulamentos." [MELLO, 2016, p. 379]

5 "Quando o ato é concreto caracteriza-se, em oposição aos abstratos, por ser aplicável uma única vez, pois só se aplicará àquela concreta situação. Vale dizer: o ato se esgota na produção de uma única relação jurídica. Seu significado em Direito, que é o de ser fonte de efeitos, exaure-se de imediato. $\mathrm{O}$ ato não será fonte de nada mais. Portanto, extingue-se. O que perdura é o fluxo de efeitos que gerou, ou seja: a relação jurídica produzida.

Nestes casos, a invalidação quer eliminar - e com frequência retroativamente o que ainda existe: a relação jurídica. Do ato não há mais cuidar, pois desapareceu com sua aplicação concreta, isto é, única.

Em síntese: a invalidação quando referida a atos ineficazes tem por objeto o próprio ato; quando referida a atos eficazes abstratos tem por objeto o ato e seus efeitos; e quando referida a atos eficazes concretos tem por objeto apenas os efeitos deles." [MELLO, 2016, p. 479]

6 "O ato administrativo não fica a produzir efeitos qual uma fonte a verter água. $\mathrm{O}$ ato num dado instante, produz efeito. A produção (eficácia) é sempre instantânea. $\mathrm{O}$ efeito (resultado) é que permanece. $\mathrm{O}$ ato, ao cumprir sua função, produzindo o efeito típico, principal, o efeito a que fora preordenado, esgota-se. Não tendo mais possibilidade de produzir efeito algum, perde sua juridicidade, está extinto a partir de então.

Consoante essa nossa posição, o ato, como ato jurídico, só vive o período compreendido entre o instante em que se perfecciona, em que ingressa no mundo jurídico e o instante em que produz seu efeito típico. Quando, logo ao ingressar no mundo jurídico, também deflagra seu efeito típico, o ato vive apenas aquele instante.

Só é possível, portanto, falar-se em extinção do ato administrativo enquanto pendente. Com a produção de seu efeito típico o ato se consome. A partir de então, só se pode falar em extinção dos seus efeitos, cuja subsistência não reclama a sobrevivência do ato que lhes deu causa." [CAMMAROSANO, 2017, p. 369-388] 
ca por ele preordenada, extingue-se do mundo jurídico, mantendo-se incólume a relação criada ${ }^{7}$.

Como dito, aqui, estudar-se-á a extinção das relações jurídicas criadas por atos eficazes e que já geraram o seu efeito, ou seja, constituíram a relação jurídica. Contudo, para comportar todas as hipóteses, também há a possibilidade de atos administrativos eficazes, mas que ainda não geraram efeitos, isto é, que ainda não constituíram relações jurídicas, serem extintos, eles próprios (dado que relação alguma foi constituída) em decorrência de norma superveniente ${ }^{8}$.

0 recorte do estudo pretende discutir os direitos que os administrados constituem ao estabelecer com o Estado essa relação. Daí a importância de delimitar que há situações em que, a despeito de o ato administrativo ter sido produzido com validade, ele ainda não produziu seus efeitos e, portanto, não criou a relação jurídica entre administrado e Administração. Nessas situações, outra norma pode ser constituída no mundo jurídico (uma decisão judicial, por exemplo) para evitar que a relação jurídica seja criada. Ao ser criada a relação entre administrado e Estado, no entanto, o ato administrativo se extingue, restando no mundo jurídico apenas o seu efeito, qual seja, a relação jurídica.

Agora é possível delimitar com maior precisão o objeto em análise: trata-se de analisar os efeitos da extinção das relações jurídicas estabelecidas por atos administrativos concretos produzidos validamente em face dos direitos dos administrados. Isto é, pretende-se responder à seguinte pergunta: quando e como pode - e quais as consequências para os administrados de - ser extinta a relação jurídica criada por ato administrativo concreto produzido regularmente?

\footnotetext{
${ }^{7}$ Afasta-se, portanto, o posicionamento de parcela da doutrina que compreende que a extinção de uma norma do mundo jurídico não pode ser realizada por acontecimentos do mundo jurídico ou por outra norma: "Nos termos dantes explicados, uma norma sai do mundo jurídico basicamente em duas hipóteses: ( 1) quando outra norma a retira (é o caso, por exemplo, da invalidação e da revogação); (2) quando um acontecimento a retira do mundo jurídico (é o caso, por exemplo, do estabelecimento pela própria norma do tempo de sua vigência; quando ela se destina a fim certo e determinado e este vem a ocorrer)" [MARTINS, 2019, p. 388]

8 "É possível, porém, que o ato administrativo seja eficaz e, apesar disso, não haja a instituição de nenhuma relação jurídica. O ato eficaz - insiste-se - é o dotado de eficácia normativa, ou seja, é aquele que tem aptidão para incidir: basta estar presente a possibilidade de incidência, não se exige, para a eficácia do ato, que tenha ocorrido a efetiva incidência. Se presentes as condições fáticas e jurídicas para a incidência, essa não ocorrerá enquanto não ocorrer a hipótese descrita no antecedente normativo. Assim, em relação ao ato administrativo eficaz (abstrato ou concreto) que, por força da não ocorrência da hipótese descrita em seu antecedente, ainda não tenha incidido, o objeto da extinção também será tão somente a própria norma, ou seja, o próprio ato.

Por fim, se o ato administrativo for eficaz e tiver ocorrido a hipótese descrita em seu antecedente, haverá automática incidência e, consequentemente, instituição da relação jurídica descrita no consequente" [MARTINS, 2019, p. 387]
} 


\section{Formas de extinção dos efeitos do ato administrativo concreto}

Dispostas acima as premissas que embasam o questionamento elaborado, cumpre determinar agora quais são as distintas formas de extinção consagradas pela doutrina especializada. Compreender a distinção entre fatos e atos jurídicos é o primeiro passo para o estudo da extinção das relações criadas por ato administrativo concreto 9 .

Pode a relação jurídica estabelecida pelo ato administrativo concreto ser extinta ou por algum fato juridicamente relevante para o Direito ou por outra norma jurídica. Há também a possibilidade de a relação jurídica ser extinta por declaração do próprio administrado. Ademais, se extinta a relação jurídica por outra norma jurídica, devem ser distintos os efeitos típicos dos reflexos ${ }^{10}$.

Veja-se quatro situações exemplificativas com base na hipótese nomeação de diretor para ocupar cargo de chefia em empresa estatal, típico cargo em comissão ${ }^{11}$,

\footnotetext{
${ }^{9} \mathrm{O}$ professor Ricardo Marcondes Martins, ao separar atos de fatos administrativos, leciona: "O fato administrativo é um acontecimento do mundo fenomênico a que o Direito atribui efeitos jurídicos. $O$ ato, sendo uma declaração, pressupõe uma situação comunicativa e, pois, um emissor, no exercício de função administrativa, e um receptor, o administrado. (...)

O fato administrativo não declara nada, ele simplesmente acontece, ocorre no mundo fenomênico." [MARTINS, 2019, p. 86]

${ }^{10}$ Evidentemente, não há que se falar em extinção de ato administrativo por efeito atípico prodrômico, mas somente por efeito atípico reflexo. Os conceitos são apresentados com maestria por Celso Antônio Bandeira de Mello, a despeito de o tratamento se referir aos efeitos reflexos do ato administrativo, é fácil transpor o conceito para as demais normas jurídicas: "Distinguem-se os efeitos típicos, ou próprios, dos efeitos atípicos. Os primeiros são efeitos correspondentes à tipologia específica do ato, à sua função jurídica. Assim, é próprio do ato de nomeação habilitar alguém a assumir um cargo; é próprio ou típico do ato de demissão desligar funcionário do serviço público. Os efeitos atípicos, decorrentes, embora, da produção do ato, não resultam de seu conteúdo específico.

Os efeitos atípicos podem ser de dupla ordem: efeitos preliminares ou prodrômicos e efeitos reflexos. Os preliminares existem enquanto perdura a situação de pendência do ato, isto é, durante o período que intercorre desde a produção do ato até o desencadeamento de seus efeitos típicos. Serve de exemplo, no caso dos atos sujeitos a controle por parte de outro órgão, o dever-poder que assiste a este último de emitir o ato controlador que funciona como condição de eficácia do ato controlado. Portanto, foi efeito atípico preliminar do ato controlado acarretar para o órgão controlador o dever-poder de emitir o ato de controle.

Efeitos reflexos são aqueles que refluem sobre outra relação jurídica, ou seja, que atingem terceiros não objetivados pelo ato. Quer-se dizer: ao incidir sobre uma dada situação, o ato atinge outra relação jurídica que não era seu objeto próprio. Os efeitos reflexos, portanto, são aqueles que alcançam terceiros, pessoas que não fazem parte da relação jurídica travada entre a Administração e o sujeito passivo do ato. É o caso do locatário de imóvel desapropriado. Neste bom exemplo de Flávio Bauer Novelli, nota-se que, perdido o imóvel pelo proprietário desapropriado (sujeito passivo do ato expropriatório), o locatário vê rescindida a relação jurídica de locação que entretinha com o ex-proprietário (efeito reconhecido no art. 5o, parágrafo único, da Lei 8.245, de 18.10.1991). É lógico que o efeito típico da desapropriação foi destituir a propriedade de seu dominus, e não rescindir a locação. Este é mero efeito reflexo da desapropriação" [MELLO, 2016, p. 401]

11 "Decorrência lógica do exposto é que as empresas estatais, que estão abrangidas pelo dever de realizar concurso público, dele estarão isentas, à semelhança da Administração direta e autárquica, quando o posto for de direção, chefia e assessoramento. Em outros termos, nas empresas estatais também pode haver cargo em comissão - obviamente sob o regime de emprego." [SUNDFELD; SOUZA, 2006, p. 36]
} 
isto é, criação por ato administrativo de uma relação jurídica entre o Estado e o administrado que assumiu o cargo.

Pode a relação jurídica ser extinta pelo falecimento do diretor, fato administrativo. Pode a relação jurídica ser extinta pela renúncia do diretor, declaração do particular. Pode ser extinta pela exoneração do diretor, efeito típico do ato administrativo de exoneração. Pode, ainda, ser extinto por lei que determine a extinção da própria empresa estatal: a extinção da empresa estatal é o efeito típico da norma jurídica legislativa, ao passo que a extinção dos cargos em comissão e, dentre eles, o do diretor, é efeito reflexo.

Exemplificados para fins de aclaração do conteúdo, mister compreender que se excluiu da análise a extinção de atos ineficazes, haja vista que eles não chegam a constituir qualquer relação jurídica. Ficam excluídos da análise, portanto, a revogação de ato ineficaz e a "recusa do beneficiário, cuja aquiescência era necessária para produção de seus efeitos" [MELLO. 2016, p. 464]. Esta última fica excluída da análise justamente porque é o próprio administrado, por vontade própria, quem recusa a formalização da relação jurídica possível, não havendo o que se tratar de qualquer outro direito.

De toda a sorte, com relação à retirada de ato ineficaz, pertinente a posição adotada por Antônio Carlos Cintra do Amaral ${ }^{12}$. Para fins de ato administrativo, devem ser considerados somente os "postos", o que significa dizer, aqueles que possuem eficácia, que instituem relações jurídicas. A "mera retirada", retirada de ato administrativo ineficaz não atinge relações jurídicas, é apenas a interrupção de um processo de formação do ato, não constitui direito ao administrado.

Mister ressalvar, no entanto, que esse conceito não pode ser subvertido, isto é, não pode ser utilizado como mera retirada se revogação for. Se a mera retirada por razões de conveniência e oportunidade atingir alguma relação jurídica - não se estará mais a tratar de mera retirada, mas sim de revogação e, portanto, dessa forma deve ser tratada. A subversão do conceito para negar direito aos administrados é uma afronta ao ordenamento jurídico e deve ser repudiada pelas esferas competentes.

Aproveitando-se o panorama da extinção dos atos administrativos elaborado por Celso Antônio Bandeira de Mello $^{13}$, tem-se que o ato eficaz extingue seus efeitos (i)

\footnotetext{
12 "O ato administrativo (norma jurídica) extingue-se quando é eliminado do sistema jurídico, ou é substituído, expressa ou tacitamente, por outro ato com conteúdo diverso ou incompatível com o do ato anterior.

Nesse sentido - e voltando à distinção e entre inexistência de ato administrativo, ato administrativo inválido e ato administrativo válido - entendo que só se pode falar em extinção de ato administrativo posto. Assim, ressalvo desde logo que não considero modalidade de extinção de ato administrativo a mera retirada que é a meu ver a interrupção do processo de formação da declaração estatal" [AMARAL, 2008, p. 71].

${ }^{13}$ MELLO, 2016, pp. 462-465: “item XIV. Panorama da extinção dos atos administrativos" do capítulo VII.
} 
com o cumprimento do objetivo preconizado pela relação jurídica: por seu esgotamento, pela execução material prevista na relação jurídica criada, por termo final ou por condição resolutiva; (ii) com a renúncia do administrado; (iii) com o desaparecimento do conteúdo (sujeito ou objeto que se relacionava com a Administração Pública) da relação jurídica; e (iv) por emissão de nova norma jurídica.

Quanto ao (i) cumprimento dos efeitos de ato administrativo concreto, não há nada a se acrescentar com relação aos direitos do administrado. Cumprido os efeitos da relação jurídica criada pelo ato, ela se exaure e os direitos do administrado ali contemplados estão preservados. De antemão, importa falar que essa confirmação voltará a ser útil no tópico 3 deste estudo.

Quanto à (ii) extinção por renúncia do administrado, valem os mesmos comentários realizados sobre a recusa: a vontade do administrado em renunciar à relação jurídica a extingue e, evidentemente, por ter se tratado de vontade do administrado, estão preservados os seus direitos. A diferença está na existência de uma relação jurídica que se finda com a renúncia, ao passo que, na recusa, a relação não chega a existir ${ }^{14}$.

Inclusive, o conceito de não existência é relevante quanto à (iii) extinção da relação jurídica por desaparecimento do sujeito ou do objeto. Nestes casos, o desaparecimento do sujeito ou do objeto extingue a relação jurídica, haja vista que o ato administrativo havia criado uma relação jurídica entre a Administração e o sujeito ou objeto, é dizer, o ato administrativo dispunha sobre o seu conteúdo ${ }^{15}$. Desaparecido o conteúdo que se relacionava com a Administração Pública por força do ato administrativo que criou a relação jurídica, esta não existe mais.

Evidentemente, essa extinção está diretamente relacionada a fatos administrativos, isto é, com fatos do mundo do ser que têm relevância jurídica. São hipóteses que não geram direitos aos administrados perante a Administração Pública, salvo se se tratar de alguma ilicitude realizada por representantes da Administração.

Finalmente, mister tratar da extinção da relação jurídica (iv) por norma superveniente. Costumeiramente, diz-se que pode ocorrer retirada de cinco modos: invalidação, cassação, revogação, derrubada/contraposição e decaimento/caducidade.

Um novo recorte, contudo, é necessário por limitação de espaço e para àquilo que pretende este estudo. Como se está a tratar de atos válidos, evidentemente não se

\footnotetext{
${ }^{14}$ É a posição de Márcio Cammarosano, confira-se: "Os atos suscetíveis de causar uma extinção podem consistir: a) num ato de particulares, como a renúncia e a recusa. A renúncia extingue o efeito do ato anterior e a recusa, em sendo a aceitação condição de eficácia, extingue o próprio ato, porque em estado pendência" [CAMMAROSANO, 2017, p. 369 - 388]

${ }^{15}$ O conteúdo é, para Celso Antônio Bandeira de Mello, o próprio ato: “Conteúdo - normalmente designado objeto, por muitos doutrinadores, - é aquilo que o ato dispõe isto é, o que o ato decide: enuncia, certifica, opina ou modifica na ordem jurídica. É, em suma, a própria medida que produz a alteração na ordem jurídica. Em última instância, é o próprio ato, em sua essência." [MELLO, 2016, pp. 405-406]
} 
tratará dos efeitos aos direitos dos administrados nos casos de invalidação. Similarmente, também não se tratará dos efeitos aos direitos dos administrados nas hipóteses de cassação, haja vista que ambos as hipóteses pressupõem que o administrado terá infringido a relação jurídica posta e, decerto, poderá ter, legalmente, parcela de seus direitos atingidos.

De toda a maneira, esclareça-se: tanto em uma quanto em outra a relação jurídica é extinta porque sobreveio nova norma jurídica, administrativa ou judicial, que invalida ou cassa (total ou parcialmente) a relação jurídica dantes formalizada. 0 efeito típico dessa nova norma é extinguir a relação jurídica anterior ou porque ela padeceu de nulidade desde sua constituição ou porque ela foi prejudicada por ato ilícito do particular.

Já com relação à revogação e à derrubada, é certo que são possibilidades de extinção da relação jurídica por efeitos típicos de outros atos administrativos. Isto é, o que se pretende com a emissão dos atos administrativos de revogação ou de derrubada é a extinção da relação jurídica criada por outro ato administrativo.

Na revogação, trata-se de ato exarado pela mesma competência que criou a relação jurídica anterior. Alteradas as condições fáticas, aqui entendidas amplamente, há novo motivo que permite a reavaliação da conveniência e oportunidade de manutenção ou não daquela relação jurídica. Resta evidente que a revogação extingue, por seus efeitos típicos, a relação jurídica criada por outro ato administrativo concreto.

Similarmente, mas editada por competência distinta, a derrubada, ou contraposição, somente é possível quando novo ato tiver a intenção típica de extinguir a relação jurídica outrora criada. Neste caso, pode, similarmente à revogação, decorrer de situação em que haja juízo de discricionariedade, como no caso clássico da exoneração de funcionário em cargo de comissão; como pode decorrer de situação vinculante, evidenciado, e.g., na situação de aposentadoria compulsória por limite de idade.

Veja-se que aqui há discordância quanto ao magistério de Ricardo Marcondes Martins, mas cuja citação faz-se mister para demonstrar a divergência quanto a extinção dos efeitos do ato administrativo, isto é, da relação jurídica - como aqui defende-se. Para o professor, como o ato que criou a relação jurídica ainda se mantém no mundo jurídico, a extinção por derrubada não se relaciona com a relação jurídica, mas sim com o ato anterior, razão pela qual entende o tipo de extinção em comento desta maneira:

Há casos em que a extinção não é efeito típico ou primário do ato, mas efeito reflexo ou secundário: o novo ato é emitido independentemente do precedente, por razão de outra competência, mas seus efeitos típicos são incompatíveis com os efeitos do ato anterior, gerando a extinção deste. Costuma-se dar sempre o mesmo exemplo: 
o ato de demissão do servidor derruba o ato de nomeação. Há, contudo, exemplos mais interessantes: suponha-se que o Município defira uma licença de reforma; se, antes de iniciada a obra, o órgão federal tomba o imóvel, de modo que a reforma se torne vedada, o ato de tombamento derruba a licença. A derrubada ou contraposição não configura retirada, pois o novo ato não tem por efeito típico a extinção de ato anterior. [MARTINS, 2016, pp. 325-326]

A despeito da discordância, o segundo exemplo, do tombamento decorrente de licença federal, é excelente para a continuidade deste estudo sobre os impactos aos direitos dos administrados, e ele reaparecerá mais adiante.

O decaimento, também chamado de caducidade, ocorre, segundo a doutrina consagrada, quando norma jurídica posterior torna a relação jurídica instituída por ato administrativo em desconformidade com o direito. Isto é, criada a relação jurídica em conformidade com o Direito, o ingresso de nova norma no ordenamento (seja esta nova norma, uma lei, uma decisão judicial ou um outro ato administrativo) torna a relação jurídica desconforme. É dizer, uma relação jurídica em conformidade com o Direito passa a ser considerada irregular porque outra norma jurídica foi criada.

Pretende-se demonstrar como essa explicação exige um detalhamento maior para fins da constituição da invalidade decorrente da alteração no ordenamento e as consequências de tal alteração para o direito dos administrados.

Veja-se a descrição que o professor Celso Antônio Bandeira de Mello, nomeando-a de caducidade, faz sobre a extinção dos efeitos do ato por norma jurídica superveniente:

(...) retirada porque sobreveio norma jurídica que tornou inadmissível a situação dantes permitida pelo Direito e outorgada pelo ato precedente. É a caducidade (expressão, esta, que, embora igual, nada tem a ver com a caducidade nas concessões de serviço público cf. Capítulo XII, n. 70). Exemplo: retirada de permissão para explorar parque de diversões em local que, em face da nova lei de zoneamento, tornou-se incompatível com aquele tipo de uso [MELLO, 2016, pp. 405-406]

Também aqui a intenção é utilizar o exemplo do professor para sugerir uma outra abordagem. Isso se dará, tal como no exemplo do professor Ricardo Marcondes Martins acima, no tópico 3 deste estudo.

Ainda importa explorar a definição de Antônio Carlos Cintra do Amaral que perfaz o seguinte entendimento desse fenômeno jurídico.

Um ato administrativo, produzido validamente, pode tornar-se inválido devido a uma modificação na ordem legal que lhe retire o 
fundamento de validade. É necessário, porém, que seja produzido um ato administrativo ou uma decisão judicial, constituindo a invalidade, retroagindo seus efeitos ao momento em que ocorreu a modificação na ordem legal. Essa constituição de invalidade pode, porém, ser vedada, se do ato administrativo, enquanto válido, resultou uma situação constitucionalmente protegida (art. $5^{\circ}, \mathrm{XXXVI}$, da Constituição). [AMARAL, 2008, p. 71]

Veja que é nítido o avanço na teoria no que se refere à necessidade de constituição da invalidade nos casos de decaimento. Nessa linha de raciocínio, o mestre Márcio Cammarosano trata da matéria com precisão. A construção proposta pelo professor paulista adota estes paradigmas:

De nossa parte, aceitamos o decaimento não como modalidade de extinção do ato administrativo ou de seus efeitos, como a invalidade superveniente, que dará ensejo à extinção do ato ou de seus efeitos mediante a emanação de outro ato.

Restringimos, destarte, o conceito de decaimento, de sorte a compreender apenas o fenômeno da invalidade superveniente de um ato ou relação jurídica, em virtude de modificação da ordem legal que fundamentava sua validade. (...)

Temos, para nós, que o que se verifica é a invalidade superveniente, e não uma extinção operada direta e imediatamente pela lei nova. A lei não revoga nem anula um ato administrativo. [CAMMAROSANO, 2017, p. 369-388]

A construção de Cammarosano é impecável por apresentar que o ingresso no sistema de nova norma jurídica não extingue diretamente os efeitos de atos administrativos concretos que criaram relações jurídicas com os administrados. Em verdade, o ingresso de nova norma jurídica cria a obrigação de o Estado extinguir as relações que validamente mantinha, até o ingresso de nova norma, com os administrados - como se proporá a seguir.

\section{Solução teórica proposta}

Tendo em vista que o estudo tem como foco o direito dos administrados, no decorrer do tópico 2 acima apartou-se da análise algumas formas de extinção da relação jurídica. Reveja-se para fins sintáticos.

A renúncia foi equiparada à recusa e, por se tratar de ato de vontade do particular que extingue a relação jurídica, ou recusa-a, não há que se falar em prejuízo a direito dos administrados. Em continuidade, excluindo-se atos ilícitos da Administração, o desaparecimento do conteúdo da relação jurídica como hipótese de extinção por fato administrativo não impacta direito dos administrados. 
Já ao tratar da extinção da relação jurídica por cumprimento de seus efeitos, dissese que ela realiza o direito dos administrados, oportunidade em que se ressalvou a utilidade dessa conclusão - e é o que se demonstrará neste tópico com o estudo das hipóteses de decaimento.

Ao tratar da retirada de atos administrativos, também se excluiu da análise as hipóteses decorrentes de vícios originários, haja vista, evidentemente, não serem atos válidos. Similarmente, a extinção da relação jurídica decorrente de vícios causados pelo administrado que dão ensejo à cassação também não foi analisada.

Agora, com relação à revogação, mister avançar: é corrente na doutrina a noção, incontestável, de que a revogação tem efeitos ex nunc. Isto é, o ato que, por razões de oportunidade e conveniência, extinguir a relação jurídica criada por outro ato administrativo terá efeitos, obrigatoriamente, a partir daquele momento ou, ainda, pro futuro.

Não há que se cogitar de revogação que restitua situação jurídica anterior ex tunc (incluindo a ex tunc não $a b$ initio), haja vista que adotar tal posição abalroaria o postulado da segurança jurídica de maneira definitiva. É dizer, supor ser possível outro tipo de efeito à revogação que não a ex nunc (sendo, evidentemente e como dito, possível a revogação pro futuro), seria o mesmo que permitir à autoridade competente poderes para desconstituir efeitos da relação jurídica criada por ato válido.

É também por essa razão que a derrubada ou contraposição deve ser compreendida como hipótese de extinção decorrente de norma que venha a desconstituir a relação jurídica anteriormente formada. 0 ato de derrubada desconstitui intencionalmente determinada relação jurídica. Ora, ao determinar-se a aposentadoria de determinado servidor público ou sua exoneração de cargo em comissão, não há que se falar em outra intenção que não seja a desconstituição da relação jurídica, qual seja, a de emprego que o servidor mantinha com o Estado.

É dizer, a derrubada extingue a relação jurídica anteriormente formalizada. Demonstrar-se-á, nesse sentido, que isso também deve ocorrer com o decaimento. Isto é, a entrada em vigor de uma nova norma jurídica gera a obrigação de a Administração desconstituir a relação jurídica que têm formalizada com o administrado.

A retirada de ato administrado decorrente de decaimento não pode ser compreendida como de efeitos ex nunc desde a eficácia da norma nova, salvo em casos excepcionais adiante mencionados. 0 que deve ocorrer, para que seja respeitado o direito adquirido do administrado ${ }^{16}$, em verdade, é a desconstituição pela Administração da relação jurídica que mantinha com o administrado. A motivação deste novo ato administrativo desconstitutivo é a invalidade superveniente decorrente do ingresso de nova norma jurídica do ordenamento.

\footnotetext{
${ }^{16}$ Nos termos do que prevê a Constituição da República em seu artigo 5o, inciso XXXVI.
} 
Veja-se que, até que haja desconstituição da relação, é válida a manifestação anterior do Estado. É dizer, busca-se respeitar sempre a presunção de legitimidade dos atos estatais. Se não forem desconstituídos, devem ser respeitados os efeitos produzidos anteriormente - mesmo que haja invalidade superveniente. A posição adotada se assemelha ao tratamento dado por Daniele Coutinho Talamini para a desconstituição dos efeitos de ato inválido. Confira-se a passagem:

O que o sistema jurídico tem que preservar é a situação fática já constituída - nos exemplos, o assentamento de famílias de boa-fé e a irrepetibilidade do valor recebido de boa-fé-, e não o ato inválido e que continua produzindo efeitos, o qual pode ser suprimido (até porque existe um dever de zelar pela legalidade). Não há razão para permitir que o ato inválido continue produzindo efeitos.

No caso da concessão de vantagem indevida, constatada a ilegalidade, deve a Administração invalidar o ato de concessão do benefício, suspendendo o pagamento, mas o que foi pago - dependendo da natureza da ilegalidade e do tempo já decorrido - não pode ser devolvido se houver boa-fé do servidor.

Aparentemente, tem-se, então, ato de invalidação que produz efeitos ex nunc, já que não são atingidos os efeitos passados. [TALAMINI, 2002, p. 45]

Talamini adota com precisão a posição que este estudo quer defender como juridicamente mais correta: o ato de invalidação - e aqui há a aproximação dos casos de invalidação originária com os decorrentes de alteração superveniente - produz efeitos ex nunc, sem atingir os efeitos passados. Mas, mais do que isso, essa posição reforça que o que se pretende desconstituir é a relação jurídica. Veja-se que é exatamente isso o que a autora transcrita, acertadamente, demonstra: a relação jurídica se mantém intangível até que seja desconstituída.

A linha é semelhante à posição externada por Márcio Cammarosano e transcrita ao final do tópico 2 deste estudo. E, por essa razão, pergunta-se: se há necessidade de ato de desconstituição que implique em extinção da relação jurídica, há razão na diferenciação entre decaimento e derrubada? Cammarosano expôs o seguinte ao final do mencionado artigo:

O decaimento não se confunde, portanto, com os atos de invalidação ou de anulação, constituindo, assim, apenas um fenômeno que enseja a produção de outro ato, jurisdicional (anulação) ou administrativo (invalidação). Este outro ato é que extingue o ato anterior, ou a relação jurídica por ele constituída, que se tornou incompatível com a nova ordem legal. [CAMMAROSANO, 2017, p. 369-388] 
Parece claro, com as devidas vênias de estilo com os posicionamentos dissonantes, que a comunicação ao administrado de que sua relação jurídica anteriormente constituída por ato administrativo válido e concreto fora extinta é similar em ambos os casos, seja de derrubada, seja do que a doutrina comumente denomina de decaimento.

Veja-se que no tópico anterior tratou-se, de maneira exemplificada, da hipótese de retirada decorrente de situação que exige juízo de discricionariedade, como na exoneração de servidor em cargo de comissão - mas também de hipótese de retirada em casos vinculantes, é dizer, em casos em que há exigência legal que obriga a desconstituição da relação jurídica formalizada entre administrado e Estado.

Ora, a consequência prática da aproximação é esta: similarmente à retirada de ato administrativo descrita como derrubada vinculante, a desconstituição da relação jurídica decorrente de decaimento também gera sempre efeitos ex nunc e precisa ser declarada e comunicada ao administrado.

As exceções são os três casos de decaimento tratados, com exímio acerto, por Fábio Mauro de Medeiros como de hipóteses necessárias de decaimento [MEDEIROS, 2009, p. 133], quais sejam, quando lei revogada regulava o direito originário como sujeito ao regime de precariedade; quando há a extinção de instituto jurídico perpétuo; ou quando houver inovação na ordem jurídica decorrente de lei que tipifique comportamentos.

A despeito do acerto quanto às exceções, a definição proposta por Medeiros de que o decaimento "é o ato administrativo que extingue um ato administrativo anterior pela ocorrência de inovação do ordenamento jurídico, por uma nova legislação, restringindo ou proibindo, total ou parcialmente, o que outrora era permitido" [MEDEIROS, 2009, p. 177] não nos parece que abarca a totalidade do fenômeno jurídico.

A derrubada é o ato administrativo que tem a intenção de extinguir relações jurídicas formadas anteriormente por outro ato administrativo concreto. Como já repisado, a derrubada pode decorrer tanto de uma competência discricionária, como a exoneração de cargos em comissão ${ }^{17}$, quanto de uma competência vinculada, nos casos em que o ordenamento jurídico assim o exige.

E é nessa linha de raciocínio que os exemplos de decaimento dos professores Ricardo Marcondes Martins e Celso Antônio Bandeira de Mello mencionados no tópico 2 devem ser comentados. 0 primeiro trouxe à baila o exemplo, transcrito supra, de licença de reforma deferida por Município, que é derrubada em virtude de o órgão federal ter tombado o imóvel. Já o mestre Bandeira de Mello traz este exemplo,

\footnotetext{
${ }^{17}$ Veja-se que por ser precária a relação jurídica estabelecida entre o Estado e os comissionados, qualquer legislação que eventualmente extinga tais cargos não exigirá nova manifestação do Estado para extinguir a relação criada.
} 
também acima transcrito: retirada de permissão para explorar parque de diversões em local que, em face da nova lei de zoneamento, tornou-se incompatível com aquele tipo de uso.

Em ambos os casos exemplificados não resta claro quais são os efeitos do decaimento para os administrados. 0 professor Ricardo Marcondes Martins tangencia a questão nestes termos:

O estudo do decaimento ou caducidade foi praticamente desprezado pela doutrina. Esta se debruçou sobre o tema da invalidação. Nos termos expostos, em ambos os casos a extinção decorre de uma exigência do Direito. Em ambos, o ato contraria o Direito, globalmente considerado: na invalidação, desde o momento de sua introdução no sistema normativo; no decaimento ou caducidade, a partir de um momento superveniente. Por força dessa similitude com o fundamento da invalidação, boa parte da teoria desta estende-se, mutatis mutandis, à teoria do decaimento ou da caducidade. Exemplo: a teoria da modulação de efeitos da invalidação, a seguir exposta, é perfeitamente extensível ao decaimento ou caducidade. Ademais, de modo similar à invalidade originária, a invalidade superveniente por alteração das circunstâncias fáticas ou jurídicas, não leva, necessariamente, à retirada do ato, ou seja, à caducidade ou ao decaimento; pode levar à sua alteração. Da mesma forma que o sistema normativo pode exigir ou facultar a modificação do ato originariamente inválido, tema explorado no capítulo seguinte, também pode exigir ou facultar a modificação 0 ato supervenientemente inválido. [MARTINS. 2019, p. 342]

É com escorreito acerto que o professor trata das questões de estabilização dos vícios decorrentes de invalidade superveniente. Contudo, é necessário afirmar a posição tendo em vista o direito dos administrados de confiar legitimamente na presunção de validade dos atos administrativos: qualquer declaração de desconstituição da relação jurídica criada anteriormente por ato concreto válido terá efeitos ex nunc.

Novamente os exemplos: se não há comunicação ao particular que teve a licença deferida de que houve um tombamento pelo órgão federal e ele executar a reforma, ele está sujeito a alguma penalidade? Alterando-se brevemente o segundo exemplo: se uma licença para operar barraca de venda de alimentos em região cuja nova lei de zoneamento não permite qualquer comércio não é desconstituída, devem os efeitos de desconstituição futura afetar quaisquer direitos do comerciante? Parece ser negativa a resposta para ambas as perguntas. As situações acima precisam ser tratadas com maior cautela pela doutrina. 
As três exceções, elencadas com escorreita precisão por Fábio de Medeiros, são as únicas em que não há necessidade de desconstituição expressa da relação jurídica criada por ato administrativo concreto e válido.

Fora tais exceções, a ocorrência de decaimento obriga a Administração a, por meio de ato administrativo de competência vinculada, desconstituir relação jurídica formada anteriormente por outro ato administrativo válido. Nesse sentido, a relação jurídica instituída por ato administrativo válido e concreto assim se mantém até que o administrado seja comunicado do decaimento. A comunicação, geralmente, dar-se-á por novo ato administrativo emitido pela Administração Pública com quem o administrado mantém relação.

A formulação acima ainda comporta, para evitar tanto a constituição de absurdos jurídicos quanto potencial abuso do direito, algumas derradeiras conclusões, que passam a ser formuladas.

Em magistral ensaio sobre o regime jurídico das licenças, o professor Luís Manuel Fonseca Pires traz a seguinte reflexão sobre a possibilidade de indenização de administrado que, por força de interesse público superveniente, tem licença cassada.

Em que pese o interesse público superveniente ser passível de imposição ao administrado e, em razão da supremacia do interesse coletivo, prevalecer em detrimento do direito individual do titular da licença, é preciso ponderar que se trata de verdadeiro sacrifício de direito, (...) no qual o ordenamento jurídico autoriza - no caso, em razão do interesse público superveniente - o perecimento de um direito individual.

Portanto, por se tratar de um sacrifício de direito o administrado que detém o direito que a licença lhe confere deve ser previamente indenizado, por aplicação por analogia do art. $5^{\circ}$, XXIV, da Constituição Federal, que exige justa e prévia indenização em dinheiro nos casos de desapropriação por necessidade ou utilidade pública, ou por interesse social. [PIRES, 2006, p. 202]

Ou seja, se o administrado tem direito à indenização por decorrência de direito outrora garantido por força da relação jurídica que fora constituída por ato administrativo concreto, certo é que essa situação também deve se refletir, dado que juridicamente idêntica, às de decaimento aqui tratadas.

Veja-se, nesse sentido, o exemplo do caso de tombamento: se o tombamento federal não foi informado por ato administrativo ao administrado que detinha a licença da reforma, isto é, se ainda não foi emitido o ato que derrube a licença, nada obsta que algum terceiro interessado o informe. Nessa hipótese, é certo que não se poderá alegar desconhecimento do Direito. 
Assim, é certo que o administrado que tomar conhecimento de situação que torne sua relação jurídica estabelecida com a Administração inquestionavelmente em desconformidade com o Direito não pode alegar desconhecimento. É dizer, na hipótese de o administrado comprovadamente tomar conhecimento - até por notificação de terceiros - de alteração no ordenamento que implique no fim da sua relação jurídica com o Estado, certo é que ao administrado não é permitido continuar atuando como se a relação existisse, sob pena de má-fé. Na situação acima, compete ao administrado buscar o Estado para eventual ressarcimento.

As formulações complementares pretendem, acima de tudo, demonstrar que a afirmação de que a inovação normativa dá ensejo à desconstituição das relações jurídicas com efeitos ex nunc é evitar que administrados de boa-fé sejam penalizados por situações que criam estar legalmente respaldados. Pretende-se reforçar a importância da comunicação ao administrado para que sua relação jurídica seja desconstituída. Em razão disso, também é necessário separar as situações de decaimento entre pessoas jurídicas e físicas.

Quanto às pessoas físicas, parece claro que o Direito exige a manutenção da relação jurídica até a desconstituição em razão de invalidade superveniente. Já com relação às pessoas jurídicas, necessário evitar incorrer no erro acima mencionado, qual seja, o do abuso do direito.

Evidente que, e.g., se é alterada norma em âmbito federal sobre construção civil, não podem empresas desse ramo alegar desconhecimento da matéria e se apoiar em licenças concedidas previamente à alteração. Para ficar claro: se relacionada à atividade-fim da pessoa jurídica, há uma razão, prima facie, para ser considerado que o decaimento era conhecido. Se versar sobre outra atividade, o desconhecimento é presumível e deve a Administração Pública desconstituir a relação maculada pela norma superveniente.

Ainda, para esgotar, se, por exemplo, empresa ligada ao ramo de tecnologia precisar extrair espécime arbóreo de sua propriedade em razão de uma reforma e, para tanto, recebe licença de 6 meses para executar a extração, a promulgação neste tempo de norma administrativa federal que proíba a extração dessa espécime só tornará inválida a licença se a empresa for comunicada da alteração. Se não o for e a extração for realizada, não há que se falar em qualquer punição. A remoção do espécime extinguiria a relação jurídica por cumprimento dos efeitos - como se adiantou acima - e nada poderia ser feito pela Administração para punir a suposta infração de norma federal haja vista que a relação jurídica que permitia a extração não havia sido desconstituída.

Se a mesma situação se relacionasse a uma empresa que fosse do ramo ambiental, evidentemente não poderia ser alegado o desconhecimento, dado que seria presumível, por tratar-se de atividade-fim, que se conhecesse. 
A importância de serem explorados exemplos hipotéticos que testam a teoria é, para além de prová-la, expor a compreensão de que, por mais que o Direito tente garantir segurança jurídica às relações, situações limítrofes exigirão do intérprete competente a análise do caso concreto. A previsibilidade que os estudos teóricos tentam impor ao Direito nunca terá o condão de esgotar todas as situações possíveis.

Percebe-se que a intenção dessa releitura aqui proposta é compreender a presunção de legitimidade dos atos administrativos em consonância com o direito dos administrados. A lição da professora Lúcia Valle Figueiredo enuncia esse mesmo raciocínio:

No Direito Público, exatamente pela presunção de legitimidade dos atos administrativos, a conservação de alguns atos, ainda que viciados, encontra arrimo nos princípios gerais. Hão que ser conciliados os interesses individuais e coletivos. [FIGUEIREDO, 2008, p. 259]

Assim sendo, o decaimento, nos limites teóricos propostos neste estudo, pode ser definido como o instituto jurídico que cria a obrigação de o Estado rever suas relações jurídicas - que serão mantidas até que o administrado seja comunicado. Somente com essa clareza será respeitado integralmente o direito dos administrados que estabeleceram uma relação jurídica com o Poder Público.

Há evidente aproximação com a retirada de atos administrativos por derrubada, dado que a desconstituição da relação jurídica precisa ser comunicada. Todavia, a deferência ao legislador e o respeito à divisão tripartite das funções estatais impõem a separação dos conceitos de derrubada e decaimento justamente porque, neste último, é possível prever algumas situações, como acima hipoteticamente descritas, em que a relação ainda não foi desconstituída pela Administração Pública, mas há conhecimento da nova norma pelo administrado.

O que se pretende com a aproximação dos conceitos é evitar que administrados de boa-fé sejam prejudicados com desconstituições de direitos adquiridos sob a justificativa de que outra norma sobreveio e aniquilou sua relação jurídica. É justamente com esse viés que é possível determinar que a relação jurídica formalizada por ato válido constitui direito adquirido do administrado e somente é desfeita, concedida a possibilidade de indenização se o caso concreto assim demandar, quando comunicada por ato do Estado com quem era mantida a relação - ou, excepcionalmente, por terceiros. Assim, a melhor compreensão do fenômeno jurídico exige a aproximação dos conceitos de retirada e decaimento/caducidade para serem evitadas arbitrariedades na aplicação do Direito, respeitando-se o direito dos administrados. 


\section{Referências bibliográficas}

AMARAL, Antônio Carlos Cintra do. Teoria do ato administrativo. Belo Horizonte: Fórum, 2008.

CAMMAROSANO, Márcio. Decaimento e extinção dos atos administrativos. In: Revista de Direito Administrativo e Infraestrutura | vol. 3/2017 | p. 369 - 388 | Out - Dez / 2017.

FIGUEIREDO, Lúcia Valle. Curso de Direito Administrativo. 9a ed. rev., ampl. e atual. até a Emenda Constitucional 56/2007. São Paulo: Malheiros Editores, 2008.

MARTINS, Ricardo Marcondes. Tratado de Direito Administrativo - v5: ato administrativo e processo administrativo. 2a ed. São Paulo: Revista dos Tribunais, 2019.

MEDEIROS, Fábio Medeiros de. Extinção do Ato Administrativo em Razão da Mudança de Lei - Decaimento. Belo Horizonte: Editora Fórum, 2009.

MELLO, Celso Antônio Bandeira de. Ato Administrativo e Direitos dos Administrados. São Paulo: Revista dos Tribunais, 1991.

. Curso de Direito Administrativo. 33a ed. rev. e atual. até a Emenda Constitucional 92, de 12.7.2016. São Paulo: Malheiros Editores, 2016.

PIRES, Luís Manuel Fonseca. Regime Jurídico das Licenças. São Paulo: Quartier Latin, 2006.

SUNDFELD, Carlos Ari; SOUZA, Rodrigo Pagani de. As Empresas Estatais, o Concurso Público e os Cargos em Comissão. In: Revista de Direito Administrativo, São Paulo: Atlas, v. 243, set./dez. 2006.

TALAMINI, Daniele Coutinho. Revogação do Ato Administrativo. São Paulo: Malheiros Editores, 2002. 